\title{
Introducing Dr. and Mrs. Steeves
}

by Harvey Beck, Saskatoon

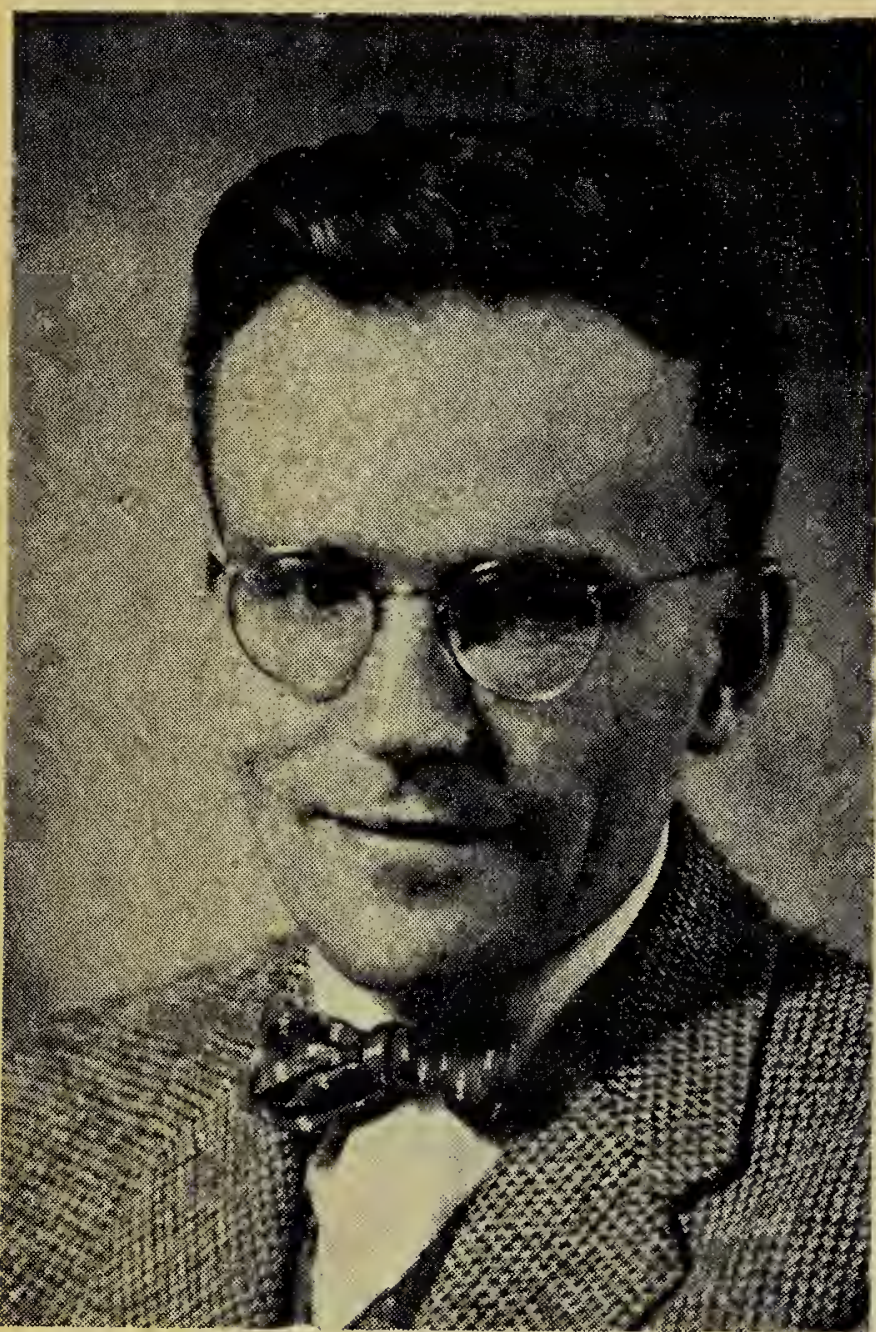

Dr. TAYLOR STEEVES

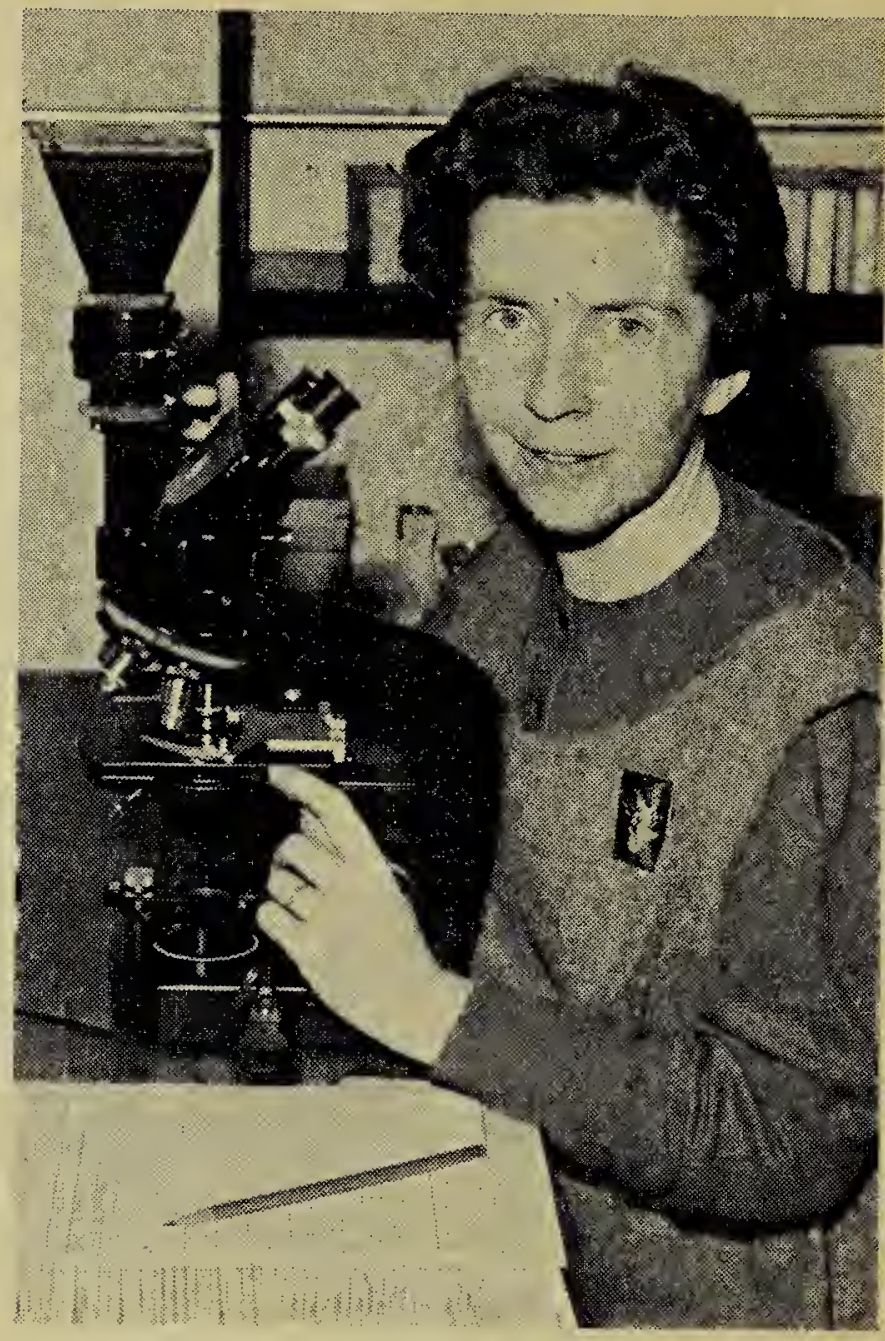

Dr. MARGARET STEEVES

Saskatchewan has recently been very fortunate in obtaining the services of Dr. and Mrs. Taylor Steeves.

Dr. Steves was born in Quincy, Mass. He obtained his B.S. degree from the University of Massachusetts in 1947 and his Ph.D. from Harvard in 1951. He was a Junior Fellow of the Society of Fellows, Harvard, for three years. From 1954 until he came to join the Biology Department at the University of Saskatchewan, Dr. Steeves was assistant professor of botany at the Biological Labs., Harvard University.

Dr. Steeves is particularly interested in experimental morphology. His work deals with the development of morphological characters in vascular plants. Plant organs and tissues arise from embryological regions called meristems. Dr. Steeves has been studying meristems in an attempt to find out how the developmental processes occur and how these processes are controlled. At present he is working with the meristematic

tissues of ferns and with the prairie "crocus."

Mrs. Margaret Seeves took her undergraduate training at Douglas College in New Jersey and obtained her Ph.D. from Radcliffe College. She is now working as a research associate in the Geology Department of the University of Saskatchewan. Canada's only woman paleobotanist, she is currently examining pollen and spores taken from shale formed millions of years ago from which she will gain a valuable statistical record of vegetational changes, both evolutionary and climatic. By means of this pollen analysis it is possible to trace far back into geological time the origin of various plant groups.

Members of the Saskatoon Natural History Society have already had the pleasure of meeting Dr. and Mrs. Steeves; we hope many in the provincial society will meet them at our society's meetings, and that we shall often find contributions from them in the Blue Jay. 